Journal of Applied Pharmaceutical Science Vol. 3 (09), pp. 029-035, September, 2013

Available online at http://www.japsonline.com

DOI: $10.7324 /$ JAPS.2013.3906

ISSN 2231-3354 (cc) BY-NC-SA

\title{
Therapeutic effects of standardized fenugreek seed extract on experimental urolithiasis in rats
}

\author{
Chinmay U. Kapase ${ }^{1}$, Subhash L. Bodhankar ${ }^{1, *}$, Vishwaraman Mohan ${ }^{2}$, Prasad A. Thakurdesai ${ }^{2}$ \\ ${ }^{1}$ Department of Pharmacology, Poona College of Pharmacy, Bharati Vidyapeeth Deemed University, Erandwane, Paud Road, Pune-411 038, India. \\ ${ }^{2}$ Department of Scientific affairs, Indus Biotech Private Limited, 1, Rahul Residency, Off Salunke Vihar Road, Kondhwa, Pune-411 048, India.
}

\begin{tabular}{l}
\hline ARTICLE INFO \\
\hline Article history: \\
Received on: $13 / 08 / 2013$ \\
Revised on: $05 / 09 / 2013$ \\
Accepted on: $22 / 09 / 2013$ \\
Available online: $30 / 09 / 2013$ \\
\hline
\end{tabular}

Key words:

Fenugreek; trigonelline; therapeutic; urolithiasis; ethylene glycol; calcium oxalate.

\begin{abstract}
The objective of the present study was to investigate therapeutic efficacy of standardized fenugreek seed extract with trigonelline as marker (SFSE-T) in experimental urolithiasis in rats. Effects of subacute oral treatments of SFSE-T (30 and $60 \mathrm{mg} / \mathrm{kg}$ ) and reference anti-urolithiasis drug, Cystone $(750 \mathrm{mg} / \mathrm{kg}$ ) were evaluated against $0.75 \%$ ethylene glycol (EG) and $1 \% \mathrm{w} / \mathrm{v}$ ammonium chloride (AC) induced urolithiasis in rats. The biochemical (urinary and serum) and histopathological parameters were investigated. Subacute oral treatment of SFSE-T (60 $\mathrm{mg} / \mathrm{kg}$ ) showed reversal of EG+AC induced changes in urine (decreased 24-h urine output, $\mathrm{pH}$, excretion of creatinine, citrate, and chloride and increased uric acid and oxalate excretion) and serum (increased creatine, uric acid and blood urea nitrogen) parameters and decreased creatine clearance. Histopathology examination of the kidneys sections from SFSE-T $(60 \mathrm{mg} / \mathrm{kg})$ treated rats showed lowered number of crystals, cell damage and tubulointerstitial damage index as compared with EG+AC control rats. Standardized fenugreek seed extracts showed promising therapeutic effect against experimental urolithiasis in rats.
\end{abstract}

\section{INTRODUCTION}

Urolithiasis (stones formation in urinary system) is a global problem and spans all geographic regions of the world. A kidney stone (calculus) is a solid concretion or crystal aggregation formed in the kidneys from dietary minerals in the urine. Kidney calculi formation during urolithiasis is a complex process that results from a succession of several physicochemical events, which include supersaturation, nucleation, growth, aggregation, and finally retention within the kidneys. Management of kidney calculi depends on the size and location of the stones. Most currently used therapies aim at altering the physical and chemical properties of urine to prevent super saturation of urinary components, which results in their precipitation and ultimately stone formation (Moe et al., 2011). Stones larger than $5 \mathrm{~mm}$ or stones that fail to pass through; are treated by some surgical interventional procedures such as extracorporeal shock wave

\footnotetext{
* Corresponding Author
}

Dr. Subhash L. Bodhankar, PhD

Professor and Head, Department of Pharmacology, Poona College of Pharmacy, Bharati Vidyapeeth Deemed University, Erandwane, Paud Road, 411038, Pune, India, Tel. +91-20-24537237 (Ext. 29),

Fax - +91-20-25439386, lithotripsy, ureteroscopy or percutaneous nephrolithotomy (Park and Pearle, 2007). However, most people show recurrence (Nabi et al., 2007) and the need for improved drugs with therapeutic (curative) actions exist. Many plants have been traditionally used in management of kidney stones and have modern experimental evidence of anti-urolithic activity. For example, fenugreek (Trigonella foenum-graecum L. Family: Fabaceae) seeds have been used by traditional herbalists for problems of kidney and male reproductive tract (Snehlata and Payal, 2012). Along with several health benefits, fenugreek seeds is known to protect kidney morphology and improve renal functions in diabetes mellitus (Xue et al., 2011) and dieldrin- (Hfaiedh et al., 2012) induced nephrotoxicity. Trigonelline (N-methylnicotinic acid, N-methyl betaine) is the major alkaloid phytoconstituent of fenugreek seeds. Recently, we have reported renoprotective effects of trigonelline based standardized fenugreek seeds extract in animal model of diabetic nephropathy with and without renal ischemic reperfusion in rats (Arora et al., 2012). Trigonelline is reported to have protective actions against diabetic peripheral hypertensive nephropathy (a renal function disorders) by suppression of oxidative stress in kidney and reduction in renal cell apoptosis and fibrosis (Ghule et al., 2012) and down regulation of mitochondrial 
electron transfer system related gene expressions (Yoshinari et al., 2013). Generation of free radicals is known as a major mediator of pathologic consequences behind calcium oxalate $(\mathrm{CaOx})$ type of kidney calculi (Dal Moro et al., 2005), which is predominant (> 90\% cases) amongst all types of kidney calculi.(Park and Pearle, 2007). Increased oxidative stress in mitochondria and associated injury to the renal tubules often prelude the stone formation (Khand et al., 2002). Furthermore, trigonelline get excreted unchanged in urine (Zeiger and Tice, 1997) and available for action during urinary disorders such as urolithiasis.

The prophylactic activity of powder (Ahsan et al., 1989) and aqueous extract (Laroubi et al., 2007) of fenugreek seeds on $\mathrm{CaOx}$ urine stone formation in rats have been reported. Looking at recurrence problem of existing anti-urolithic agents (Nabi, Downey, 2007), effective and safe agent with therapeutic antiurolithiasis activity is in need. Increased diuresis, antioxidant activity and lowering of urinary concentrations of stone forming constituents are suggested mechanism for anti-urolithiatic effects of fenugreek seeds with need of further exploration for responsible chemical constituents (Laroubi, Touhami, 2007). However, such exploratory studies on fenugreek seed extract for active constituent or therapeutic action not yet reported.

Therefore, the present study was undertaken with an objective to evaluate therapeutic activity of standardized fenugreek seed extract with trigonelline as marker (SFSE-T) in wellvalidated and clinically relevant model of urolithiasis in rats.

\section{MATERIALS AND METHODS}

\section{Animals}

Male Wistar rats (250-300 g) were purchased from National Toxicology Centre, Pune, India. The animals were housed at a temperature of $25 \pm 1{ }^{\circ} \mathrm{C}$ and relative humidity of 45 $55 \%$ under 12:12 light:dark cycle. The animals had free access to feed pellets (Amrut Laboratory Animal Feed, Nav Maharashtra Chakan Oil Mills Ltd., Sangli, Maharashtra, India) and tap water ad libitum. All observations were made between 9:00 and 17:00 h in a quiet room, at $23-26^{\circ} \mathrm{C}$.

The Institutional Animal Ethics Committee approved the study protocol (CPCSEA/19/2010). All experiments were performed in accordance with the guidelines recommended by Committee for Control and Supervision of Experimentation on Animals (CPCSEA), Government of India.

\section{Chemicals}

EG (Loba Chemie Private Limited, Mumbai, India), and ammonium chloride, AC (Merck Specialties Private Limited, Mumbai, India) were purchased from respective vendors. Cystone (a polyherbal formulation of Himalaya Drug Company, Bangaluru, India) was used a positive control and purchased locally. Cystone suspension in distilled water was prepared daily and administered at dose of $1 \mathrm{mg} / \mathrm{kg}$. All other chemicals and reagents used were of analytical grade and procured from approved chemical suppliers.

\section{The test compound}

The test compound, SFSE-T was prepared as per the reported procedure (Gaur et al., 2013) and supplied by Indus Biotech Private Limited, Pune, Maharashtra, India. SFSE-T is a hydroalcoholic extract (water: ethyl alcohol in proportion of 30:70) of fenugreek seeds, enriched by column chromatography for the marker compound trigonelline hydrochloride $(82 \% \mathrm{w} / \mathrm{w})$. SFSE-T solution was freshly prepared daily as a $1 \%$ aqueous solution in distilled water and administered to mice orally at a dose of $1 \mathrm{mg} / \mathrm{kg}$.

The oral doses 30 and $60 \mathrm{mg} / \mathrm{kg}$ of test compound, SFSE-T, were based on earlier research (Gaur, Bodhankar, 2013) and acute oral toxicity (AOT) study conducted in adult male rats according to a guideline (AOT 425) of Organization for Economic Co-operation and Development (OECD) using up and down procedure.

\section{Induction of kidney calculi and treatment schedule}

Induction of kidney calculi was done by EG and AC in rats as per reported procedure (Divakar et al., 2010). The male Wistar rats (150-250 g) were randomly divided into five groups of six animals each. Group I served as a vehicle control and was maintained on regular rat food and drinking water ad libitum and received distilled water $(1 \mathrm{ml} / \mathrm{kg}$, po). All remaining groups (group II to $\mathrm{V}$ ) received calculi inducing treatment for 28 days, comprising of $0.75 \% \mathrm{v} / \mathrm{v}$ EG with $1 \% \mathrm{w} / \mathrm{v} \mathrm{AC}$ in drinking water for 3 days to accelerate lithiasis followed by only $0.75 \% \mathrm{v} / \mathrm{v}$ EG for next 25 days. Group II served as lithiasis control (EG+AC control) and received distilled water $(1 \mathrm{ml} / \mathrm{kg}$, po). Group III (Cystone-750) was the positive control group and received Cystone treatment $(750 \mathrm{mg} / \mathrm{kg}$, p.o). Groups IV and V (SFSE-T-30 and SFSE-T-60) received the test compound SFSE-T at a dose of $30 \mathrm{mg} / \mathrm{kg}$ and $60 \mathrm{mg} / \mathrm{kg}$ respectively. All treatments were given orally from 15 th day of start of study to 28 th day.

\section{Urine collection and analysis}

On selected days, rats were placed individually in metabolic cages (Techniplast, Milan, Italy) and 24-h urine was collected on day 0,14 and 28 of study and used to assess various urine parameters namely $24-\mathrm{h}$ volume, $\mathrm{pH}$ and levels of creatinine, uric acid, oxalate, magnesium citrate, sodium, potassium and chloride using established procedures (Hald, 1947, Varcoe, 2001).

\section{Blood withdrawal and serum analysis}

On last day of experiment (Day 28), rats were anaesthetized using anesthetic ether and blood was withdrawn by retro-orbital puncture using micro capillary tubes. Serum was separated by centrifugation at $7000 \mathrm{rpm}$ for $15 \mathrm{~min}$ at $4{ }^{\circ} \mathrm{C}$. The creatinine, uric acid and blood urea nitrogen (BUN) measurements were performed using semi autoanalyzer (Microlab-300, Merck, India). Creatinine clearance ( $\mathrm{CCr}$ ) was calculated by Cockcroft formula (Cockcroft and Gault, 1976): (urine creatinine (mg/dl) X 24-h urine output (ml))/(serum creatinine (mg/dl) X 1440). 


\section{Histopathology analysis of kidney}

Animals were sacrificed on the 28th day and kidneys were isolated, cleaned and washed in cold physiological saline. Kidneys were fixed, processed and embedded in wax. Sections (5 $\mu \mathrm{m})$ were stained with hematoxylin and eosin and examined under a light microscope.

Tubulointerstitial damage index (TDI) was measured under microscope and graded as grade 0 to 3 where, grade 0 was no change; grade 1, lesion involving $25 \%$; grade 2 , lesion affecting $25 \%$ to $50 \%$; and grade 3 , lesion involving $>50 \%$ of the field as per reported procedure (Rothermund et al., 2001) and represented as mean TDI.

\section{Statistical analysis}

Results were expressed as Mean \pm standard error of mean (SEM). The statistical analysis was performed using the Prism software v.6.0 (Graph Pad Inc., U.S.A). The data was considered significant at $\mathrm{p}<0.05$. Separate Two-Way Analysis of Variance, (ANOVA) followed by Bonferroni Posttest was used for each urine parameters. Separate One-Way ANOVA followed by Dunnett's test was used for each serum parameters. The data for TDI was analyzed by Kruskal-Wallis test followed by Dunn's Multiple Comparisons Test.

\section{RESULTS}

\section{Effect of treatments on water consumption and urine parameters}

The data of water consumption and urine parameter measurements such as $24-\mathrm{h}$ volume, $\mathrm{pH}$, uric acid and creatinine is presented as Table 1.

There was no change in water consumption in any group of rats during the study. On day-14 of the study, EG+AC control group showed significant $(\mathrm{P}<0.001)$ decrease in 24-h urine volume, urine $\mathrm{pH}$ and urine creatinine levels whereas significant increase was found in levels of uric acid. These lithiasis-induced changes were significantly $(\mathrm{P}<0.001)$ reversed by cysteine and SFSE-T $(60 \mathrm{mg} / \mathrm{kg})$ treatment group whereas reversing effects of SFSE-T (30 mg/kg) treatment was limited to urine $\mathrm{pH}$.

\section{Effect of treatments on electrolyte excretion in urine}

The data obtained from urinary excretion of electrolytes (oxalate, citrate, chloride, sodium and potassium) is presented in Table. 2. EG+AC treatment was found to cause significant $(\mathrm{P}<$ $0.001)$ increase in urinary excretion of oxalate. On day-28 of the study, cystone and both doses of SFSE-T (30 and $60 \mathrm{mg} / \mathrm{kg}$ ) caused significant decrease in oxalate excretion as compared with $\mathrm{EG}+\mathrm{AC}$ control group.

Urine excretion of citrate, chloride, sodium and potassium were decreased significantly $(\mathrm{P}<0.001)$ in $\mathrm{EG}+\mathrm{AC}$ treated rats as compared to normal rats. Therapeutic treatment of cystone and SFSE-T (60 mg/kg) but not SFSE-T (30 mg/kg) significantly $(\mathrm{P}<0.001)$ restored urinary excretion of citrate and chloride. Execration of urinary sodium did not restored by any treatment. Excretion of urinary potassium was significantly $(\mathrm{P}<$ 0.01) restored by cystone treatment. However, SFSE-T (30 or $60 \mathrm{mg} / \mathrm{kg}$ ) did not restore urinary excretion of sodium or potassium.

\section{Effect of treatments on serum parameters}

The data of serum parameters (creatinine, uric acid and BUN) and creatinine clearance as measured on day-28 of the study is presented as Table. 3. Significant $(\mathrm{P}<0.001)$ increase was observed in serum levels of creatine, uric acid and BUN as compared with normal rats. Cystone and SFSE-T $(60 \mathrm{mg} / \mathrm{kg})$ showed significant $(\mathrm{P}<0.01$ and $\mathrm{P}<0.001)$ reversal of elevated levels of serum parameters.

However, SFSE-T $(30 \mathrm{mg} / \mathrm{kg})$ treatment did not show such reversal in serum parameters. EG+AC treatment showed significant $(\mathrm{P}<0.001)$ reduction in creatine clearance as compared to normal rats on day-14 of the experiment. Cystone and SFSE-T at $60 \mathrm{mg} / \mathrm{kg}$ (but not dose of $30 \mathrm{mg} / \mathrm{kg}$ ) showed significant recovery of creatinine clearance after 14-days of treatment (on day 28 of study).

\section{Effect of treatments on kidney histology}

The representative photomicrographs from sections of kidneys from experimental rats are presented as Fig. 1. The section from normal rats (Fig. 1A) showed normal architecture of kidney with no deposition of crystals or histological damage. The section from EG+AC control rats (Fig. 1B) showed deposition of high number of crystals (small arrows), marked interstitial inflammation of lymphocytes and monocytes, interstitial fibrosis , cloudy change in tubular epithelial cells, intra-tubular casts and exfoliated epithelial cells.

Fig. 1C is enlarged view (40X) of EG+AC control rat and showed detailed view of architectural damage (small arrow) with crystals (Fig. 1D) showed section of cystone $(750 \mathrm{mg} / \mathrm{kg}$ ) treated rat with minimal deposition of crystals, mild histological damage with minimal interstitial inflammation of lymphocytes, cloudy change in tubular epithelial cells. Fig. 1E represents the section of SFSE-T $(30 \mathrm{mg} / \mathrm{kg})$ treated rat and showed medium deposition of crystals, moderate congestion and hemorrhage with acute tubular necrosis. F represents section of kidney from SFSE-T $(60 \mathrm{mg} / \mathrm{kg})$ treated rat and showed mild deposition of crystals, mild histological damage (black arrow) and minimal interstitial damage in tubular epithelial cells.

As shown in Fig. 2, kidney of EG+AC control rats showed increase in the TDI (Mean TDI $=2.5$ ) as compared with normal rats (mean TDI $=0.0$ ). After 14 days of treatment, as compared to EG+AC control group, TDI was significantly ( $\mathrm{P}<$ $0.05)$ reduced by cystone and SFSE-T $(60 \mathrm{mg} / \mathrm{kg})$ treatment to 0.67 and 0.67 respectively. However, SFSE-T (30 $\mathrm{mg} / \mathrm{kg})$ treatment did not show significant reduction as compared to $\mathrm{EG}+\mathrm{AC}$ group. 
Table. 1: Effect of treatments on urine parameters in EG+AC induced kidney calculi in rats.

\begin{tabular}{|c|c|c|c|c|c|c|}
\hline Treatment & Day & Normal & EG+AC control & Cystone-750 & SFSE-T-30 & SFSE-T-60 \\
\hline \multirow{3}{*}{ Water consumption $(\mathrm{ml} / 24 \mathrm{~h})$} & 0 & $46.67 \pm 4.94$ & $48.33 \pm 4.77$ & $40.00 \pm 0.00$ & $60.00 \pm 3.65$ & $51.67 \pm 4.77$ \\
\hline & 14 & $34.17 \pm 7.35$ & $33.33 \pm 3.33$ & $40.83 \pm 6.38$ & $50.00 \pm 2.58$ & $32.50 \pm 2.50$ \\
\hline & 28 & $34.17 \pm 3.75$ & $36.67 \pm 4.22$ & $20.00 \pm 3.65$ & $40.00 \pm 3.42$ & $25.00 \pm 3.42$ \\
\hline \multirow{3}{*}{ 24-h Urine volume $(\mathrm{ml} / 24 \mathrm{~h})$} & 0 & $12.27 \pm 0.41$ & $12.78 \pm 0.16$ & $12.59 \pm 0.54$ & $13.37 \pm 0.27$ & $12.76 \pm 0.65$ \\
\hline & 14 & $12.48 \pm 0.31$ & $9.46 \pm 0.26^{\# \# \# ~}$ & $8.67 \pm 0.14$ & $8.67 \pm 0.51$ & $9.33 \pm 0.15$ \\
\hline & 28 & $12.92 \pm 0.46$ & $7.68 \pm 0.31^{\# \# \#}$ & $10.48 \pm 0.13^{* * *}$ & $8.88 \pm 0.70$ & $10.20 \pm 0.08^{* * *}$ \\
\hline \multirow{3}{*}{ Urine $\mathrm{pH}$} & 0 & $7.13 \pm 0.04$ & $7.2 \pm 0.02$ & $7.16 \pm 0.04$ & $7.16 \pm 0.04$ & $7.03 \pm 0.07$ \\
\hline & 14 & $7.1 \pm 0.06$ & 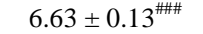 & $6.63 \pm 0.08$ & $6.75 \pm 0.05$ & $6.65 \pm 0.07$ \\
\hline & 28 & $7.18 \pm 0.07$ & 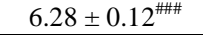 & $7.05 \pm 0.02^{* * * *}$ & $6.68 \pm 0.12^{* *}$ & $7.05 \pm 0.04^{* * * *}$ \\
\hline \multirow{3}{*}{ Uric Acid (mg/dL) } & 0 & $0.92 \pm 0.04$ & $0.88 \pm 0.02$ & $0.89 \pm 0.02$ & $0.85 \pm 0.01$ & $0.87 \pm 0.01$ \\
\hline & 14 & $0.91 \pm 0.01$ & $1.35 \pm 0.05^{\# \# \#}$ & $1.33 \pm 0.02$ & $1.57 \pm 0.02^{* * *}$ & $1.55 \pm 0.02^{* * *}$ \\
\hline & 28 & $0.91 \pm 0.02$ & 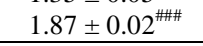 & $1.03 \pm 0.05^{* * * *}$ & $1.53 \pm 0.009^{* * *}$ & $1.12 \pm 0.06^{* * *}$ \\
\hline \multirow{3}{*}{ Urine Creatinine (mg/dl) } & 0 & $64.31 \pm 0.86$ & $63.58 \pm 0.81$ & $63.45 \pm 0.70$ & $63.47 \pm 0.69$ & $63.80 \pm 0.89$ \\
\hline & 14 & $63.48 \pm 0.95$ & $38.86 \pm 0.67^{\# \# \#}$ & $37.02 \pm 0.63$ & $36.38 \pm 0.95$ & $36.45 \pm 1.40$ \\
\hline & 28 & $62.56 \pm 0.87$ & $29.70 \pm 0.22^{\# \# \#}$ & $42.46 \pm 0.6^{* * * *}$ & $31.34 \pm 1.09$ & $39.15 \pm 0.39^{* * *}$ \\
\hline
\end{tabular}

Values are expressed as mean \pm SEM. $(n=6)$, Data was analyzed by separate Two-Way ANOVA followed by Bonferroni Posttest for each parameter. ns- not significant, ${ }^{\# \#} \mathrm{p}<0.001$ as compared with Normal group, ${ }^{* *} \mathrm{p}<0.01,{ }^{* * *} \mathrm{p}<0.001$ as compared with $(\mathrm{EG}+\mathrm{AC})$ group on respective days.

Table. 2: Effect of treatments on urinary excretion of electrolytes in EG+AC induced kidney calculi in rats.

\begin{tabular}{|c|c|c|c|c|c|c|}
\hline Treatment & Day & Normal & EG+AC control & Cystone-750 & SFSE-T-30 & SFSE-T-60 \\
\hline Oxalate & 0 & $0.54 \pm 0.02$ & $0.53 \pm 0.04$ & $0.52 \pm 0.02$ & $0.63 \pm 0.07$ & $0.61 \pm 0.03$ \\
\hline \multirow{2}{*}{$(\mathrm{mg} / \mathrm{ml})$} & 14 & $0.47 \pm 0.05$ & $4.10 \pm 029 \# \# \#$ & $4.04 \pm 0.15$ & $3.72 \pm 0.14$ & $3.76 \pm 0.11$ \\
\hline & 28 & $0.53 \pm 0.06$ & $5.96 \pm 0.29 \# \# \#$ & $1.64 \pm 0.09 * * *$ & $4.27 \pm 0.24 * * *$ & $2.41 \pm 0.17 * * *$ \\
\hline Citrate & 0 & $12.27 \pm 0.41$ & $12.78 \pm 0.16$ & $12.59 \pm 0.54$ & $13.37 \pm 0.27$ & $12.76 \pm 0.65$ \\
\hline \multirow[t]{2}{*}{$(\mathrm{mg} / \mathrm{ml})$} & 14 & $12.48 \pm 0.31$ & $9.46 \pm 0.26 \# \# \#$ & $8.67 \pm 0.14$ & $8.67 \pm 0.51$ & $9.33 \pm 0.15$ \\
\hline & 28 & $12.92 \pm 0.46$ & $7.68 \pm 0.31 \# \# \#$ & $10.48 \pm 0.13^{* * *}$ & $8.88 \pm 0.70$ & $10.20 \pm 0.08 * * *$ \\
\hline \multirow[t]{3}{*}{ Chloride (mEq/L) } & 0 & $371.66 \pm 4.77$ & $358.33 \pm 13.76$ & $376.66 \pm 33.03$ & $356.66 \pm 30.40$ & $363.33 \pm 12.01$ \\
\hline & 14 & $351.66 \pm 9.09$ & $151.66 \pm 21.04 \# \# \#$ & $213.33 \pm 25.25$ & $183.33 \pm 8.02$ & $165.00 \pm 9.91$ \\
\hline & 28 & $348.33 \pm 11.08$ & $65.00 \pm 6.19 \# \# \#$ & $258.33 \pm 14.92 * * *$ & $105 \pm 8.46$ & $193.33 \pm 6.66^{* * * *}$ \\
\hline Sodium & 0 & $129.94 \pm 4.38$ & $120.17 \pm 9.57$ & $125.60 \pm 2.57$ & $114.15 \pm 12.85$ & $123.77 \pm 2.93$ \\
\hline \multirow[t]{2}{*}{$(\mathrm{mEq} / \mathrm{L})$} & 14 & $124.99 \pm 2.58$ & $57.10 \pm 7.53 \# \# \#$ & $51.88 \pm 7.27$ & $59.73 \pm 9.90$ & $47.72 \pm 8.71$ \\
\hline & 28 & $125.72 \pm 3.58$ & $50.30 \pm 9.81 \# \# \#$ & $86.22 \pm 18.55$ & $64.63 \pm 6.60$ & $78.53 \pm 8.77$ \\
\hline \multirow[t]{3}{*}{ Potassium (mEq/L) } & 0 & $52.48 \pm 4.60$ & $50.66 \pm 4.86$ & $50.18 \pm 1.63$ & $52.01 \pm 2.33$ & $48.71 \pm 2.69$ \\
\hline & 14 & $51.06 \pm 2.53$ & $39.88 \pm 2.23 \#$ & $40.03 \pm 1.28$ & $40.96 \pm 0.81$ & $41.2 \pm 2.11$ \\
\hline & 28 & $52.38 \pm 0.99$ & $35.01 \pm 2.63 \# \# \#$ & $48.11 \pm 1.14$ & $39.08 \pm 1.05$ & $39.66 \pm 3.13$ \\
\hline
\end{tabular}

Values are expressed as mean \pm SEM. $(\mathrm{n}=6)$, Data was analyzed by separate Two-Way ANOVA followed by Bonferroni Posttest for each parameter. \# $\mathrm{P}<$ $0.05, \# \#$, $<0.001$ as compared with Normal group, $* * \mathrm{p}<0.01, * * * \mathrm{p}<0.001$ as compared with (EG+AC) group on respective days.

Table. 3: Effect of treatments on serum parameters in EG+AC induced kidney calculi in rats at end of study.

\begin{tabular}{|c|c|c|c|c|c|}
\hline Treatment & Normal & EG+AC control & Cystone-750 & SFSE-T-30 & SFSE-T-60 \\
\hline Creatinine $(\mathrm{mg} / \mathrm{dL})$ & $1.31 \pm 0.15$ & $3.32 \pm 0.60^{\# \# \#}$ & $1.81 \pm 0.14^{* * *}$ & $3.10 \pm 0.08$ & $1.92 \pm 0.95^{* * * *}$ \\
\hline Uric acid $(\mathrm{mg} / \mathrm{dL})$ & $3.37 \pm 0.42$ & $8.13 \pm 0.73^{\# \# \#}$ & $5.38 \pm 0.55^{* * *}$ & $7.27 \pm 0.73$ & $6.37 \pm 1.40^{* *}$ \\
\hline BUN (mg/dL) & $8.07 \pm 0.42$ & 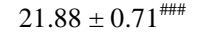 & $15.01 \pm 1.44^{* * *}$ & $21.88 \pm 1.14$ & $17.51 \pm 0.66^{* * *}$ \\
\hline Creatinine Clearance $(\mathrm{ml} / \mathrm{min})$ & $0.430 \pm 0.020$ & $0.049 \pm 0.004^{\# \#}$ & $0.172 \pm 0.009^{* *}$ & $0.062 \pm 0.004$ & $0.185 \pm 0.042^{* * *}$ \\
\hline
\end{tabular}

Values are expressed as mean \pm SEM. $(\mathrm{n}=6)$, Data was analyzed by separate One-Way ANOVA followed by Dunnett's test for each parameter. ${ }^{\# \# \# ~}<0.001$ as compared with Normal group, ${ }^{* *} \mathrm{p}<0.01,{ }^{* * *} \mathrm{p}<0.001$ as compared with $(\mathrm{EG}+\mathrm{AC})$ group on respective days.
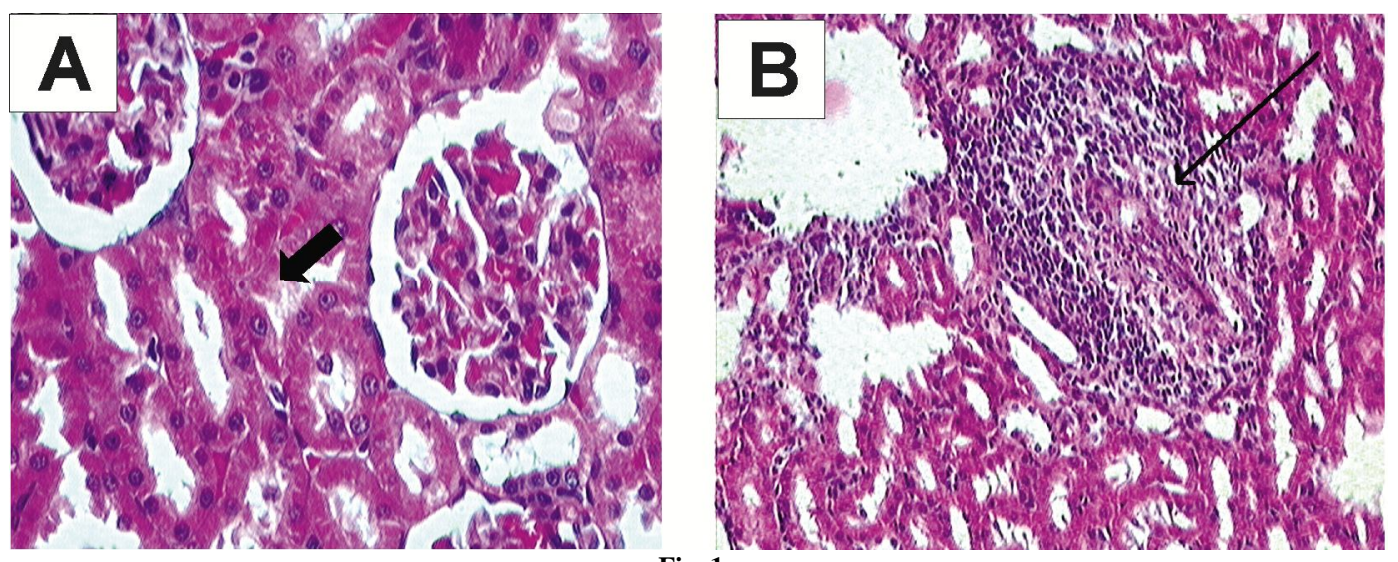

Fig. 1: 

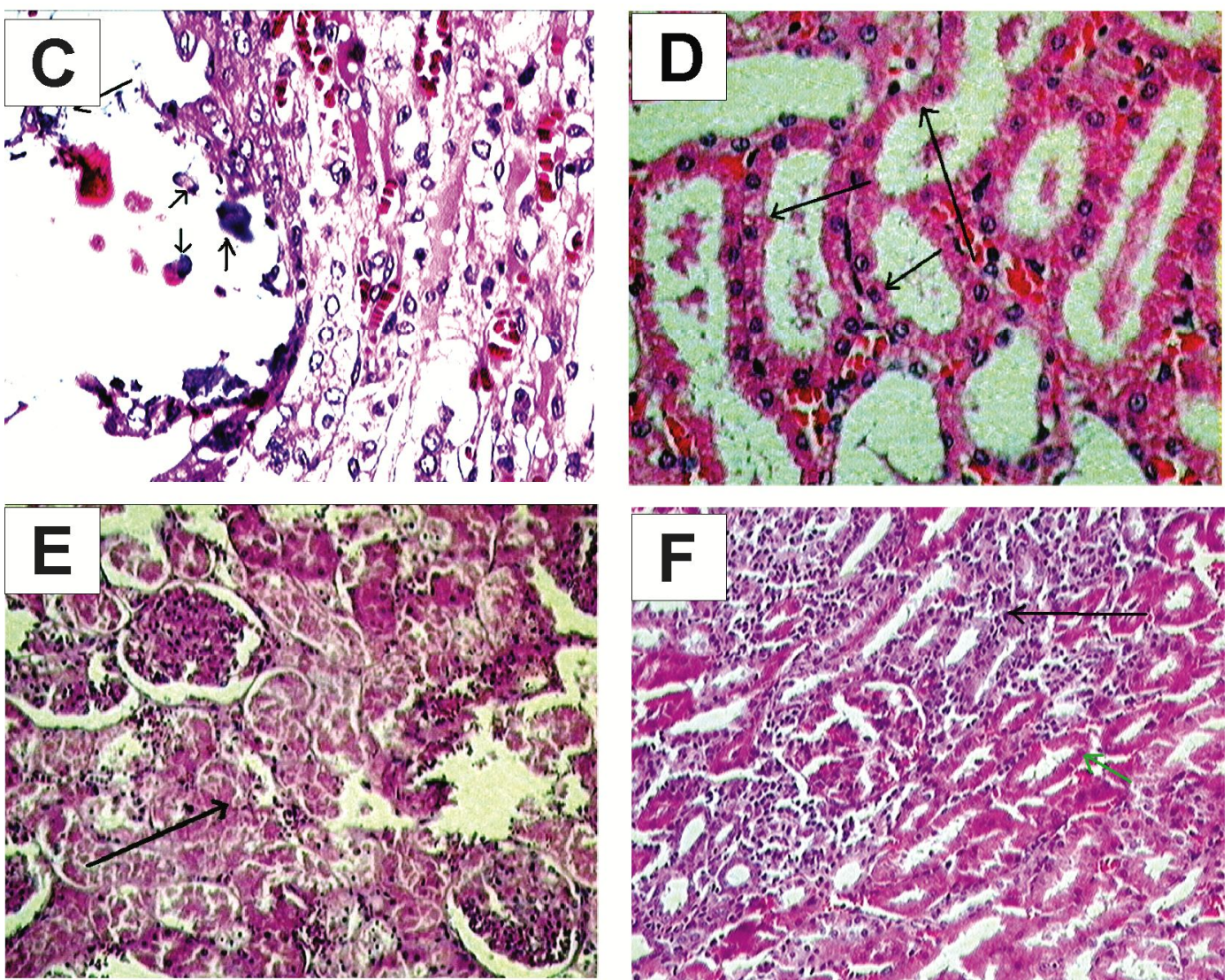

Fig. 1: Photomicrographs of sections of kidney showing architecture and calcium oxalate deposits in the kidney sections. Sections from (A) Normal (vehicle control); (B) EG+AC control (EG+AC) at $10 \mathrm{X}$ (C) EG+AC control (EG+AC) at 40X (D) Cystone-750; (E) SFSE-T-30 and (F) SFSE-T-60 group. (Staining$\mathrm{H} \& \mathrm{E}$, Magnification - $40 \mathrm{X}$ except (C)).

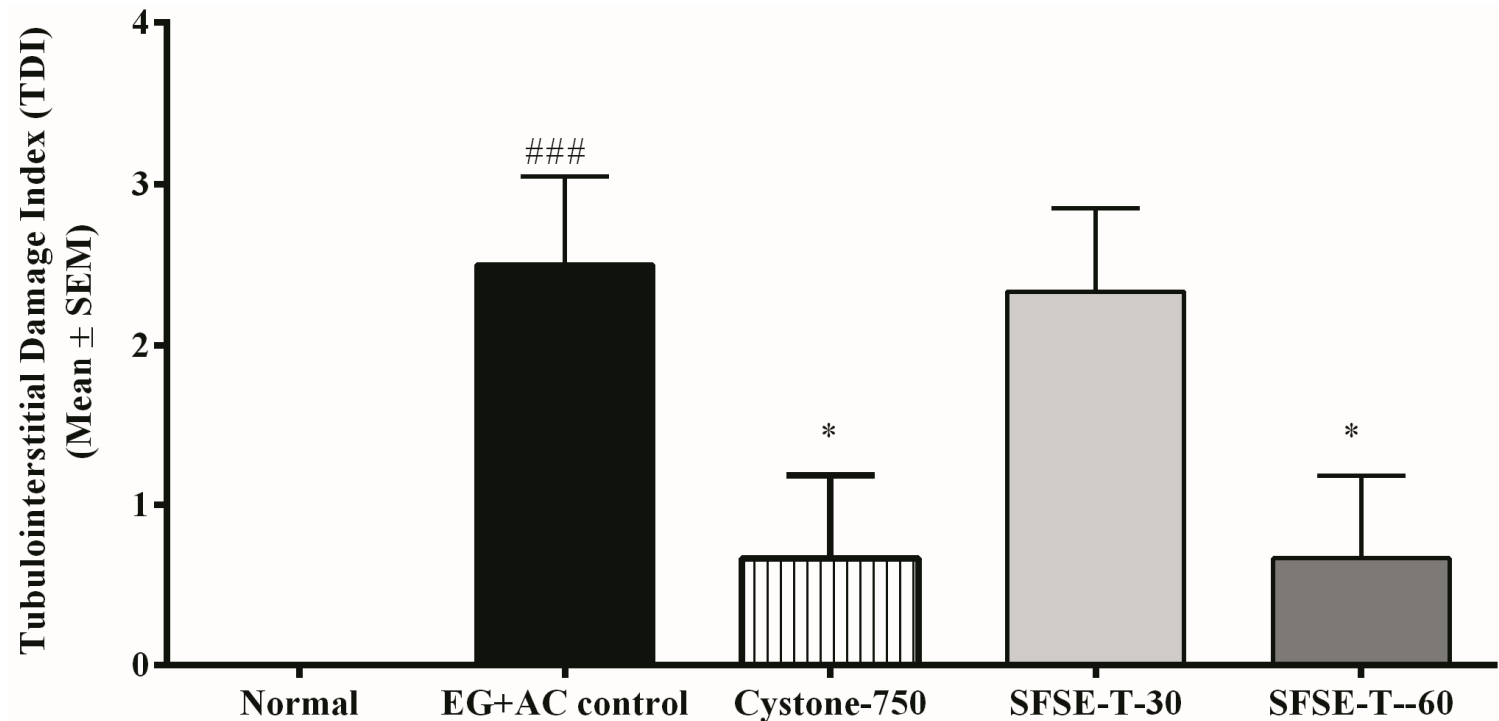

Fig. 2: Effect of treatment on Tubulointerstial damage index (TDI) from sections of kidneys. The TDI is total score obtained from tubulointerstitial damage from 10 fields on grade 0 to 3 (Grade 0 was=no changes; grade $1=$ lesion affecting $25 \%$ of the field; grade $2=$ lesion affecting $25 \%$ to $50 \%$ of the field; grade $3=$ lesion affecting 50\% of the field) for 6 mice from each group. The data was represented as Mean TDI \pm SEM and analyzed by Kruskal-Wallis test followed by Dunn's multiple comparisons test for significance. ${ }^{\# \#} \mathrm{p}<0.001$ as compared with Normal group, $* \mathrm{P}<0.05$ as compared with (EG+AC) group. 


\section{DISCUSSION}

EG induced urolithiasis model is well validated and clinically relevant. EG metabolizes into $\mathrm{CaOx}$ monohydrate (COM) and produce renal mitochondrial toxicity similar to clinical $\mathrm{CaOx}$ renal calculi (McMartin and Wallace, 2005). The prophylactic activity of aqueous extract (Laroubi, Touhami, 2007) of fenugreek seeds on $\mathrm{CaOx}$ urine stone formation in rats has been reported. In the present study, we have evaluated therapeutic activity of trigonelline based standardized extract of fenugreek seeds (SFSE-T) on renal calculi induced by EG+AC in male rats. $\mathrm{AC}$ was administered to rats along with EG to accelerate lithiasis. This combination produced kidney calculi in all the rats, which is evident from our results of increased oxalate levels and presence of stones in kidney sections within 14-days.

Urinary supersaturation with respect to stone forming constituents is considered as causative factors in calculogenesis. EG increases availability of substrate for the oxalate synthesizing enzymes, disturbs the oxalate metabolism and increases oxalate extraction, forms $\mathrm{CaOx}$ crystals and hyperoxaluria (increased renal retention and excretion of oxalate) (Selvam et al., 2001). In the present study, strong reversal of EG+AC induced hyperoxaluria by 14-day treatment of SFSE-T suggested decreased supersaturation of oxalate

Uric acid is the product of purine metabolism and is either derived from exogenous (dietary) sources or produced endogenously during cell turnover. Chronic metabolic acidosis (lowering of $\mathrm{pH}$ ) promotes uric acid extraction and kidney stone formation (Jawalekar et al., 2010). Reversal of EG+AC induced decreased urinary output and increased uric acid excretion might be result of maintenance of urinary $\mathrm{pH}$ by SFSE-T treatment.

Urine of kidney stone patients shows increased oxalate and decreased citrate, sodium, potassium and chloride (Jawalekar, Surve, 2010). The subacute treatment of SFSE-T during the present study showed beneficial and restorative effects on urinary excretion of oxalate, citrate and chloride but not of sodium and potassium. Hypokalaemia (lower urinary potassium) is known to reduce citrate excretion and promote stone formation. The lack of effect on potassium excretion (sparing effect) and beneficial changes in citrate excretion can be added advantage for SFSE-T treatment in prevention of recurrent stone formation.

Higher serum creatinine and lower $\mathrm{CCr}$ has been reported in EG+AC induced urolithiatic rats (Laroubi, Touhami, 2007). Our finding of $\mathrm{EG}+\mathrm{AC}$ induced elevated serum creatinine, uric acid and BUN and reduced $\mathrm{CCr}$ are in support of earlier reports (Laroubi, Touhami, 2007). Subacute treatment of SFSE-T (60 $\mathrm{mg} / \mathrm{kg}$ ) showed reversal in EG+AC induced serum parameters and $\mathrm{CCr}$ and confirmed kidney function improvement.

The mechanism of the EG induced stone formation and subsequent renal failure is associated with tubular cell necrosis due to EG metabolism. The end metabolite of EG is oxalic acid, the precipitation of which as $\mathrm{CaOx}$ monohydrate (COM) crystals in the tubular lumen has been linked with the renal toxicity (McMartin and Wallace, 2005). COM and excess oxalate ions stimulate an array of responses inducing localized injury and inflammation in the kidneys, damage structure of mitochondria, inhibit mitochondrial respiratory function in proximal tubular cells, alter cell permeability and lead to renal cell death (McMartin and Wallace, 2005). Trigonelline is reported to down regulate of mitochondrial electron transfer system (Yoshinari et al., 2013). Therefore, the beneficial effects SFSE-T $(60 \mathrm{mg} / \mathrm{kg})$ in improvement of $\mathrm{CCr}$ and reduction in TDI damage (as seen in histology) as compared with $\mathrm{EG}+\mathrm{AC}$ control rats in the present study can be attributed to trigonelline.

Kidney calculi are formed in a stepwise manner starting from urine supersaturation, salting out of minerals, nucleation, crystal growth, aggregation and finally retention of the crystals once they cross a particular size leading to reduced urine output (Gupta et al., 2011). During the histopathology part of present study, the number of crystals in SFSE-T $(60 \mathrm{mg} / \mathrm{kg})$ treated animal kidneys was shown to be lesser as compared with EG+AC control rats. This effect can be attributed to a multitude of properties of the marker compound of SFSE-T, trigonelline. Trigonelline is a zwitterion and is formed by the methylation of the nitrogen atom of niacin (vitamin $B_{3}$ ) (Yuyama and Suzuki, 1991). Being zwitterionic in nature, trigonelline might act as buffer, maintains urine $\mathrm{pH}$, reduced supersaturation of minerals, and prevents crystallization and stone formation.

Urolithiasis is condition of high osmolarity and dehydration stress (Gilles, 1997). The zwitterionic natural betaine compounds such as trigonelline are known osmoregulators in plants (Tramontano and Jouve, 1997) and animals.(Sizeland et al., 1993) Absorption of trigonelline from coffee is known to contribute to the glycine betaine (another osmoregulator) pool (trigonelline effects). The inhibition of resorption of glycine betaine to restores balance of solute concentration (Dellow et al., 1999) is essential for prevention of recurrence of stone formation. This "trigonelline effect" is especially relevant in conditions where urinary tract reaches high urea and salt concentrations such as urolithiasis. High concentrations of trigonelline, added under hypertonic conditions, is reported to inhibit glycine betaine accumulation in osmotically stressed Madin Darby canine kidney cells (MDCK) cells in vitro (Randall et al., 1996). Therefore, antiurolithiasis action of SFSE-T observed during the present study can be attributed to "compensatory" role of trigonelline in maintenance of glycine betaine pool and restoration of favorable solute balance.

\section{CONCLUSIONS}

In conclusion, SFSE-T, trigonelline based fenugreek seed extract, showed significant therapeutic effects against EG+AC induced urolithiasis in terms of solute balance, urinary $\mathrm{pH}$ and $\mathrm{CCr}$, TDI and number of $\mathrm{CaOx}$ crystal deposits. Since, SFSE-T is derived from fenugreek seeds (a traditional medicine and common food chain material), it can be developed as safe and effective agent for management of $\mathrm{CaOx}$ calculi and/or urolithiasis in human. However, further studies on human are warranted. 


\section{ACKNOWLEDGEMENTS}

The authors would like acknowledge Dr K. R. Mahadik, Principal, Poona College of Pharmacy, Bharati Vidyapeeth Deemed University, Pune, and Sunil Bhaskaran, MD, Indus Biotech Private Limited, Pune, India for providing necessary infrastructural and financial support to carry out the study.

\section{REFERENCES}

Ahsan SK, Tariq M, Ageel AM, al-Yahya MA, Shah AH. Effect of Trigonella foenum-graecum and Ammi majus on calcium oxalate urolithiasis in rats. J Ethnopharmacol. 1989;26:249-54.

Arora S, Bodhankar SL, Mohan V, Thakurdesai PA. Renoprotective Effects of Reconstructed Composition of Trigonella foenum-graecum L. Seeds in Animal Model of Diabetic Nephropathy with and without Renal Ischemia Reperfusion in Rats. International Journal of Pharmacology. 2012;8:321-32.

Cockcroft D, Gault M. Prediction of creatinine clearance from serum creatinine. Nephron. 1976;16:31-41.

Dal Moro F, Mancini M, Tavolini IM, De Marco V, Bassi P. Cellular and molecular gateways to urolithiasis: a new insight. Urol Int. 2005;74:193-7.

Dellow WJ, Chambers ST, Lever M, Lunt H, Robson RA. Elevated glycine betaine excretion in diabetes mellitus patients is associated with proximal tubular dysfunction and hyperglycemia. Diabetes Res Clin Pract. 1999;43:91-9.

Divakar K, Pawar AT, Chandrasekhar SB, Dighe SB, Divakar G. Protective effect of the hydro-alcoholic extract of Rubia cordifolia roots against ethylene glycol induced urolithiasis in rats. Food Chem Toxicol. 2010;48:1013-8.

Gaur V, Bodhankar SL, Mohan V, Thakurdesai PA. Neurobehavioral assessment of hydroalcoholic extract of Trigonella foenum-graecum seeds in rodent models of Parkinson's disease. Pharm Biol. 2013;51:550-7.

Ghule AE, Jadhav SS, Bodhankar SL. Trigonelline ameliorates diabetic hypertensive nephropathy by suppression of oxidative stress in kidney and reduction in renal cell apoptosis and fibrosis in streptozotocin induced neonatal diabetic (nSTZ) rats. Int Immunopharmacol. 2012;14:740-8.

Gilles R. "Compensatory" organic osmolytes in high osmolarity and dehydration stresses: history and perspectives. Comp Biochem Physiol A Physiol. 1997;117:279-90.

Gupta M, Bhayana S, Sikka SK. Role of urinary inhibitors and promoters in calcium oxalate crystallisation. International Journal of Research in Pharmacy and Chemistry. 2011;1:793-8.

Hald PM. The flame photometer for the measurement of sodium and potassium in biological materials. J Biol Chem. 1947;167:499-510.

Hfaiedh N, Alimi H, Murat JC, Elfeki A. Protective effects of fenugreek (Trigonella foenum graecum $\mathrm{L}$.) upon dieldrin-induced toxicity in male rat. Gen Physiol Biophys. 2012;31:423-30.

Jawalekar S, Surve VT, Bhutey AK. Twenty four hours urine and serum biochemical parameters in patients with urolithiasis. Nepal Med Coll J. 2010;12:5-7.

Khand FD, Gordge MP, Robertson WG, Noronha-Dutra AA, Hothersall JS. Mitochondrial superoxide production during oxalatemediated oxidative stress in renal epithelial cells. Free Radic Biol Med. 2002;32:1339-50.

Laroubi A, Touhami M, Farouk L, Zrara I, Aboufatima R, Benharref A, et al. Prophylaxis effect of Trigonella foenum graecum $\mathrm{L}$. seeds on renal stone formation in rats. Phytother Res. 2007;21:921-5.
McMartin KE, Wallace KB. Calcium oxalate monohydrate, a metabolite of ethylene glycol, is toxic for rat renal mitochondrial function. Toxicol Sci. 2005;84:195-200.

Moe OW, Pearle MS, Sakhaee K. Pharmacotherapy of urolithiasis: evidence from clinical trials. Kidney Int. 2011;79:385-92.

Nabi G, Downey P, Keeley F, Watson G, McClinton S. Extracorporeal shock wave lithotripsy (ESWL) versus ureteroscopic management for ureteric calculi. Cochrane Database Syst Rev. 2007:CD006029.

Park S, Pearle MS. Pathophysiology and management of calcium stones. Urol Clin North Am. 2007;34:323-34.

Randall K, Lever M, Peddie BA, Chambers ST. Accumulation of natural and synthetic betaines by a mammalian renal cell line. Biochem Cell Biol. 1996;74:283-7.

Rothermund L, Luckert S, Kossmehl P, Paul M, Kreutz R. Renal endothelin ET(A)/ET(B) receptor imbalance differentiates saltsensitive from salt-resistant spontaneous hypertension. Hypertension. 2001;37:275-80

Selvam R, Kalaiselvi P, Govindaraj A, Bala Murugan V, Sathish Kumar AS. Effect of A. lanata leaf extract and Vediuppu chunnam on the urinary risk factors of calcium oxalate urolithiasis during experimental hyperoxaluria. Pharmacol Res. 2001;43:89-93.

Sizeland PC, Chambers ST, Lever M, Bason LM, Robson RA. Organic osmolytes in human and other mammalian kidneys. Kidney Int 1993:43:448-53.

Snehlata HS, Payal DR. Fenugreek (Trigonella foenumgraecum L.): An Overview. International Journal of Current Pharmaceutical Review and Research. 2012;2:169-87.

Tramontano WA, Jouve D. Trigonelline accumulation in saltstressed legumes and the role of other osmoregulators as cell cycle control agents. Phytochemistry. 1997;44:1037-40.

Varcoe JS. Clinical biochemistry : techniques and instrumentation : a practical course. Singapore and London: World Scientific; 2001

Xue W, Lei J, Li X, Zhang R. Trigonella foenum graecum seed extract protects kidney function and morphology in diabetic rats via its antioxidant activity. Nutrition Research. 2011;31:555-62.

Yoshinari O, Takenake A, Igarashi K. Trigonelline ameliorates oxidative stress in type 2 diabetic Goto-Kakizaki rats. J Med Food. 2013;16:34-41.

Yuyama S, Suzuki T. The excretion of N1-methyl-2-pyridone5 -carboxylic acid and related compounds in human subjects after oral administration of nicotinic acid, trigonelline and N1-methyl-2-pyridone-5carboxylic acid. Adv Exp Med Biol. 1991; 294:475-9.

Zeiger E, Tice R. 1997. Trigonelline - Review of Toxicological Literature. Research Triangle Park, North Carolina: National Institute of Environmental Health Sciences and Integrated Laboratory Systems. p. 27.

\section{How to cite this article:}

Chinmay U. Kapase, Subhash L., Bodhankar, Vishwaraman Mohan, Prasad A. Thakurdesai., Therapeutic effects of standardized fenugreek seed extract on experimental urolithiasis in rats. J App Pharm Sci, 2013; 3 (09): 029-035. 